\title{
Customs brokers as intermediaries in international trade
}

\author{
Hege Medin ${ }^{1}$
}

Published online: 12 October 2020

(c) The Author(s) 2020

\begin{abstract}
Recent studies suggest that intermediaries like merchants facilitate international trade by reducing fixed trade costs for producers that trade through them instead of exporting or importing directly. This study argues that customs brokers-a type of intermediary rarely studied in economics before-play a similar role by reducing fixed costs of clearing goods through customs for firms that use them instead of selfdeclaring. Using panel data of Norwegian trade transactions, the paper shows that the majority of manufacturing producers participating in international trade use such brokers, and that the brokers typically handle large trade values on behalf of several different produces. In an econometric analysis, the author finds that the share of a producer's market specific trade that is self-declared rather than handled by brokers increases with the traded value. This is in line with predictions from theoretical models on trade intermediaries and holds after controlling for observed as well as unobserved factors at the producer, country and product level. Results are similar for exporting and importing, indicating that brokers facilitate both modes of trade.
\end{abstract}

Keywords International trade · Trade costs - Intermediaries · Customs brokers · Customs clearing

JEL Classification F12 $\cdot$ F14

\section{Introduction}

A recent strand in economic research concerns how intermediaries like merchants facilitate international trade by making it possible for firms unable to handle all trade-related issues by themselves to participate in international markets. This, in turn, can boost aggregated trade flows. I argue that another type of intermediary-customs brokers-can play a similar role. In Norway, all exported or imported

Hege Medin

hege.medin@nupi.no

1 Norwegian Institute of International Affairs (NUPI), St. Olavs Plass, P. O. Box 7024,

0130 OSLO, Norway 
goods must pass through customs and be declared, and a producer can choose between handling the customs declaration by itself (henceforth: self-declare) or engaging the services of a broker to do this. I use an exhaustive panel of Norwegian manufacturing producers' trade transactions containing information on usage of customs brokers. The data reveal that outsourcing of customs brokerage is very common. To my knowledge, customs brokers have rarely been studied in economics before, and this is the first article to document the use of such brokers in a whole population or even representative sample of firms.

Building on the seminal Melitz (2003) model of international trade, Ahn et al. (2011) proposed a model in which exporting firms avoid paying high fixed costs of reaching foreign customers by using a merchant (referred to as a trading company) to sell their goods in foreign markets. This comes at the expense of lower operating profits, however, as the exporter has to pay a de facto fee to the merchant (which is proportional to the traded value). Other, similar models have been proposed by scholars like Felbermayr and Jung (2011), Crozet et al. (2013), Bai et al. (2017) and Akerman (2018), focusing on, respectively, wholesaler subsidiaries; quality differences; learning by exporting and economies of scope. The survey article of Blum et al. (2018, p. 20) refers to these models jointly as the canonical model of export intermediation. The model has the feature that a third type of firm emerges in equilibrium in addition to the exporters and non-exporters in Melitz (2003). Like in that model, a producer's operating profits from exporting to a given market is proportional to the value exported, and a sorting pattern arises where only the most productive firms export, because they are the only ones that earn enough to cover the market specific fixed exporting costs. The new feature is that firms of intermediate productivity levels export indirectly through merchants, as this involves lower fixed exporting costs (but also higher variable ones). ${ }^{1}$ Consequently, the model predicts that larger and more productive producers exporting sizeable values to more profitable markets with lower trade costs are less likely to use intermediaries.

There are some empirical studies that, for selected countries, find patterns in accordance with the intermediation model. In contrast to the present study, all of these define the intermediary as a merchant like a wholesaler or retailer, and such merchants are found to account for significant shares of trade (see footnote 5). Two different approaches are used in the literature. In what will here be referred to as the intermediary approach, the intermediaries as such are compared to producers that trade without using them (henceforth: direct trading producers). Ahn et al. (2011), Crozet et al. (2013) and Akerman (2018) all used customs declaration data from, respectively, China, France and Sweden, and showed that the share of exports accounted for by merchants was larger in destination markets with lower profitability (e.g. lower GDP) and higher trade costs (e.g. higher tariffs). ${ }^{2}$ However, such data

\footnotetext{
${ }^{1}$ In some of the models, the indirect exporters do not pay a fee to the merchants, but there is a double marginalisation problem instead, which reduces their revenue from exporting indirectly instead of directly: the merchants have market power and impose a mark-up to the producer price when selling to foreign consumers.

${ }^{2}$ Using a somewhat different regression design, Bernard et al. (2015) reached a similar conclusion for Italy.
} 
typically do not contain information on the intermediary-users; that is, the producers that export or import through the merchants. The scholars were therefore not able study how producer-features affected intermediary-use.

In what will be referred to as the intermediary-user approach, in contrast, the direct trading producers are compared to producers who channel their trade through intermediaries. Studies applying this approach found that a producer's inclination to trade directly rather than via a merchant was positively associated with measures of firm level profitability, such as the number of employees (Abel-Koch 2013; Ahn et al. 2011; Maurseth and Medin 2019), labour-productivity (Ahn et al. 2011; McCann 2013; Grazzi and Tomasi 2016) and foreign ownership (Abel-Koch 2013; McCann 2013; Maurseth and Medin 2019). All these studies used firm level survey data from one or several developing countries. The data were based on interviews with producers that traded, either directly or via merchants, but not the merchant used. The scholars were therefore not able to study the intermediaries as such. Nor were they able to study how intermediary-use related to partner country characteristics, as such information was not available in the data. ${ }^{3}$ The data also had other limitations. Being based on interviews of samples of firms rather than register data, they yielded less accurate information; and they were mostly cross-sectional and hence provided limited possibilities for controlling for unobserved heterogeneity.

Fixed trade costs may not only accrue when searching for foreign contacts, but also when complying with trade and customs procedures. Grainger (2008) points out that many costs like that are fixed, as they involve, for instance, "purchase of specialist IT systems and employment of dedicated staff' (p. 26). This is also the case in Norway. The Directorate of Norwegian Customs informs that declarants must purchase special software, familiarise themselves with regulations and complete an electronic form for each declaration (shipment). Relevant certificates, like health certificates for food, must also be obtained. Further, declarants must hold customs credit, and must calculate and pay taxes and duties. ${ }^{4}$ Such customs related transaction costs are not negligible. Verwaal and Donkers (2003) found that they, on average, constituted $2 \%$ of the traded value among Dutch firms. They varied largely among firms, however, and there were indications of economies of scale. Relatedly, WTO (2016) found that border procedures were the third most important trade barrier for EU firms operating in the US (after product standards).

In the model of intermediation, the merchants face lower fixed trade costs, either by assumption or due to economies of scope. In addition, they may be better able to

\footnotetext{
3 In addition to applying the intermediary approach on Chinese customs declaration data, Ahn et al. (2011) did a separate analysis applying the intermediary-user approach on Chinese survey data. They were not able to combine these data, however. Bai et al. (2017), in contrast, combined Chinese customs declaration data for producers of rubber and plastic with other survey data for large enterprises and inferred intermediary-use from this. They studied learning effects, and like in the intermediary-user approach, they compared intermediary-users to direct exporters. However, they did not study how country- and product characteristics influenced intermediary-use, as this information was not available for the intermediary-users. Nor did they compare the intermediary-users to the intermediaries as such.

4 Information based on in depth-interviews with two representatives from the Directorate of Norwegian Customs, conducted by the author in January 2016.
} 
overcome such costs by pooling trade from many producers. Similarly, customs brokers are likely to face lower fixed customs clearance costs than produces since they specialise in handling border procedures. Furthermore, in the article it is shown that brokers handle trade from several different producers, and that each broker-handle considerably larger values than each producer. Consequently, not only merchants, but also customs brokers may facilitate trade by offering reduced fixed trade costs for producers that use their services. Using brokers is costly, however, their services must be purchased, and thus, the choice between hiring brokers and self-declare is likely to be a trade-off between fixed and variable trade costs, just as in the model of intermediation. If this holds, the predictions from that model should also be relevant for broker-use, and we should expect that producers trading small values hire brokers, and those trading large values self-declare. This prediction is studied here.

In addition to providing evidence of a new type of intermediary and focusing on a country not previously studied in this regard, this article also offers several contributions to the empirical literature on trade intermediaries. In contrast to other studies, I have in the same data information on the intermediaries themselves (customs brokers), as well as on the two types of producers; those that trade directly (selfdeclarants) and those that rely on intermediaries (broker-users). I am therefore able to merge the intermediary and intermediary-user approaches, thereby providing a more consistent and comprehensive investigation of intermediary-use.

I first use highly disaggregated data-at the declaration level, to show that there is a positive correlation between the probability of a producer self-declaring a single declaration and its trade value. This is consistent with producers avoiding fixed customs clearing costs by hiring brokers when they trade small values. The correlation may be spurious, however, and unlike other studies, I therefore control for characteristics of producers, countries and products at the same time-observed as well as unobserved-by aggregating the data and using the panel dimension. The correlation between tendency to self-declare and trade value is still positive. Apart from that, only producer level features affect intermediary-use. This contrasts studies of merchant-intermediaries, especially those using the intermediary approach, which generally found that country- and product characteristics also affected the tendency to trade directly. This underlines the importance of controlling for all these features at the same time.

Most other studies of intermediary-use, whether theoretical or empirical, have focused solely on how intermediaries facilitate exports. But, importing may also involve fixed costs that can be reduced by using intermediaries. This is likely to be the case as regards customs clearance because procedures are similar for clearing goods into as well as out of Norway. To compare the trade-facilitating role of brokers in exports and imports, I conduct all analyses for both modes of trade. In line with what a few other studies have found for merchant-intermediaries, I find that brokers-intermediaries are more commonly used in exporting than importing, and that effects are similar for the two modes of trade. ${ }^{5}$

\footnotetext{
${ }^{5}$ For example, Bernard et al. (2010) found that in the USA, $8 \%$ of the export value and $15 \%$ of import value was accounted for by wholesalers. Blum et al. (2018) found that the corresponding figures for Chile were $6 \%$ and $41 \%$, and Utar (2017) found them to be $32 \%$ and $57 \%$ for Denmark. Whereas these scholars used the intermediary approach, Maurseth and Medin (2019) applied the intermediary-user
} 
In the following, Sect. 2 discusses some concepts, Sect. 3 presents the data and provides some descriptive statistics, Sect. 4 presents empirical evidence of customsbrokers acting as trade facilitators and Sect. 5 offers some conclusions.

\section{Concepts}

This section discusses the relevance of the intermediation model for guiding the empirical analysis of the factors that influence a producer's inclination to selfdeclare in a given market (country-product combination). First, an objection to the model could be that it assumes that fixed trade costs are country-and product specific, whereas the decision to self-declare is done at the shipment level. Consequently, the fixed costs of clearing customs-at least part of them-are likely to accrue at the level of the shipment. In the context of this article, however, the crucial feature of the intermediation model is that a productivity sorting pattern arises in equilibrium due to a trade-off between fixed and variable trade costs. Several authors have built Melitz (2003) style models with trade-offs like that at the level of the shipment rather than market. More shipments yield higher total fixed shipment costs, but also lower variable costs, for instance due to lower inventory costs (Kropf and Sauré 2014). A sorting pattern does indeed arise, where only more productive producers earn enough profits from a single shipment to cover the fixed trade cost. As a consequence, higher shipment frequency implies that a higher (present value of) revenue from all shipments is required for exporting to take place. Combined with the ideas from the intermediation model, this should here imply that, ceteris paribus, producers with a larger number of shipments are less likely to self-declare. ${ }^{6}$

Another factor supporting the intermediation model is that parts of the fixed customs clearing costs are likely to accrue at country- and product level. If a declaration contains products (to/from countries) that are subject to stricter trade regulations, it becomes more complicated, and fixed costs of acquiring knowledge of how to handle it increase. Food products, for instance, are not only likely to be subject to tariffs and quotas, but often also require more documentation (in exports as well as imports). Extra documentation may also be required when trading with certain countries, for example those that have preferential agreements with Norway. In addition, a declaration may contain various products (from various sources in the case of imports), in which case the complexity of customs clearance is likely to be larger.

\footnotetext{
Footnote 5 (continued)

approach and found that in representative samples of manufacturing firms from 117 developing countries, $10.4 \%$ of the exporters and $22.8 \%$ of the importers traded solely via a merchant.

${ }^{6}$ Note, however, that larger firms have more shipments in equilibrium, and that such firms are more likely to self-declare in the intermediation model. As pointed out by an anonymous referee, it is also likely that larger firms find it easier to manipulate the number of shipments in order to minimise fixed costs. They may for instance schedule shipments so that they are able to fill whole containers in one shipment. This can put them in an even better position to self-declare, and adds to the argument that large firms are more likely to self-declare from the intermediation model.
} 
Effects like these are accounted for in the regression analysis by controlling for the number of declarations, traded products and partner countries a producer has.

It is not obvious that such measures influence negatively on the inclination to self-declare however. Any economies of scope in self-declaring pull in the opposite direction. Procedures are often similar, and the fixed costs of self-declaring in a given market may therefore decline with the producer's declaration-, product- or country scope. Indeed, Verwaal and Donkers (2003) found that customs related transaction costs decreased with transaction frequency (as well as transaction size). ${ }^{7}$

Second, it could be argued that the predictions from the intermediation model are not applicable to imports. The model regards exports, and no corresponding canonical model of import intermediation exists (Blum et al. 2018). Antràs et al. (2017) point out that Melitz-style models of exporting are not necessarily applicable for importing, as those models generally assume constant marginal production costs, which results in export decisions across markets being independent. In importing, in contrast, such decisions are likely to be interdependent because importing from an increased number of markets is likely to reduce producers' marginal production costs (because a greater variety of inputs becomes available). Even so, also in the Antràs et al. (2017) model a sorting pattern arises in equilibrium where only more productive producers import from markets with higher fixed importing cost. Combined with the ideas from the intermediation model, this should indicate a positive relationship between inclination to self-declare and trade value, also in imports. Moreover, Antràs et al. (2017) show that a reduction in market specific-fixed importing costs, under what they argue are empirically plausible assumptions, leads to an increase in the profitability of importing from all other markets. ${ }^{8}$ Again, such effects are accounted for in the regression analysis by including as controls the producer's country- and product scopes.

Third, customs clearance may not be the main reason for hiring brokers, and if so, the motive of reduced fixed trade costs can be questioned. In Sect. 3 we shall see that much of the broker-handled trade in Norway is cleared by companies in the logistics sector, in particular companies whose core activity is organisation of transport, namely freight forwarders. Other studies have found that such companies commonly handle customs clearance. Based on a survey, Andersen and Eidhammer (2009) showed that about 10-15\% of the revenue of freight forwarders handling Norwegian exports came from services other than transport, distribution and storage, and that customs handling was the largest component (also see Frémont 2009). Furthermore, studies of nonrepresentative samples of firms in the business literature reported that bundling of logistics services is very common. For example, Lieb and

\footnotetext{
7 In Akerman (2018), merchant-intermediaries possess a technology involving economies of scope, so that average export costs per product declines with the number of products exported. It is assumed that this technology is not available for producers, however. Similarly, various studies of multi-product produces have held that these face economies of scope in the number of products exported (e.g. Bernard et al. 2011).

8 As mentioned above, similar results may arise in exporting if there are economies of scope. Moreover, they may arise due to learning and network effects, which are discussed by e.g. Albornoz et al. (2012) and Chaney (2014).
} 
Bentz (2002) found that of the 500 largest US manufacturers in 2002, $65 \%$ reported using so called third-party logistics services (3PL), defined as 'the use of an outside company to perform all or parts of another company's material management or product distribution' (Leahy et al. 1995, p. 5). Langley et al. (2004), in turn, reported results from a survey among firms in North America, Western Europe, Asia-Pacific, and Latin America. Firms were (non-randomly) selected from a few manufacturing sectors and from wholesale/retail/distribution. The percentage of firms using 3PL ranged from 67 to 84 in the different regions. These studies also indicated widespread use of customs brokers. 67\% of the 3PL users studied in Lieb and Bentz (2002) outsourced customs brokerage, whereas the corresponding number ranged from 34 to $88 \%$ in Langley et al. (2004), depending on the region studied.

The data used in this article do not contain information about purchase of other services than customs clearance, but these findings may indicate that the brokerusers do in fact also purchase other logistics services from the brokers. The intermediation model should still be relevant, though. The crucial feature in this context is that the intermediary offers trade-related services likely to reduce fixed costs for producers that use them, and, as pointed out by WTO (2016), logistics costs are indeed likely to contain large fixed components. They hold that advanced logistics services require quick adaption to new technologies, ICT in particular, and that average logistics costs typically constitute a greater share of overall revenue for small than for large firms. Such firms often lack international shipment experiences and have to rely on other firms for handling logistics and transport. Though these arguments support the relevance of the intermediation model, they may imply that when the concept fixed customs clearing costs is used throughout the article it should be understood more broadly to also include other types of fixed shipment costs associated with logistics. Like pure customs clearing costs, such costs are likely to be higher for certain countries (more distant ones, for instance) or products (for example perishable food products). In the regression analysis, such differences are captured by controlling for observed as well as unobserved heterogeneity of countries and products (in addition to producers).

Fourth, the intermediation model has previously only been studied in the context of merchant-intermediaries, and there are several important differences between these and broker-intermediaries. For instance, merchants take hold of the products they trade, whereas brokers are agents who don't. A merchant's main purpose is to connect buyers and suppliers, while a broker-handle border procedures and possibly also logistics and transports. Again, however, the crucial feature is that customs brokers are likely to offer reduced fixed trade costs for producers that use them. Moreover, below we will see that the services offered by merchants and brokers are likely to be complementary; producers seldom purchase customs clearance services from merchants, and the merchants themselves often buy such services from customs brokers. ${ }^{9}$

\footnotetext{
9 Though the Norwegian data also contain information about wholesalers and retailers, it is not the purpose of this article to compare such merchant-intermediaries to the trading producers. Several studies like that have already been carried out for other countries, and such a study would suffer the same problems as those do regarding lack of information about the intermediary-users; the data do not contain information about producers selling or buying their goods to/from the merchants in Norway, and none of
} 
Table 1 Self-declared and broker-handled trade

$\begin{array}{lllll}\text { (1) } & (2) & (3)^{\mathrm{a}} & (4) & (5) \\ \text { \# of declarations } & \begin{array}{l}\text { Mean decl. } \\ \text { value }\end{array} & \begin{array}{l}\text { Median } \\ \text { decl. value }\end{array} & \begin{array}{l}\text { \# of } \\ \text { producer-year } \\ \text { obs* }\end{array} & \text { \# of producers }\end{array}$

\begin{tabular}{lrrrrr} 
Exporters & & & & \\
Self-declared trade & $2,065,799$ & 374 & 97 & 5139 & 744 \\
Broker-handled trade & $4,062,147$ & 367 & 62 & 33,034 & 7946 \\
Importers & & & & & \\
Self-declared trade & 340,335 & 354 & 99 & 7930 & 1146 \\
Broker-handled trade & $6,448,878$ & 218 & 40 & 68,833 & 15,723 \\
\hline
\end{tabular}

Norwegian trade by manufacturing producers during years 2003-2013, all observations pooled together. Values are given in 1000 (constant year 2014) NOK

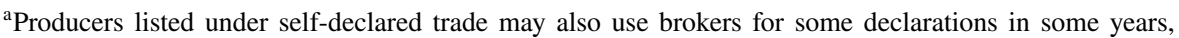
whereas producers listed under broker-handled trade always use brokers during the whole sample period. Many producers only trade during some of the sample years, and thus the (\# of producer-year observations) $<$ (\# of producers) (the number of sample years)

\section{Data and descriptives}

The dataset used for the empirical analyses is a panel that, with a few exceptions, contains all trade transactions of firms exporting and importing goods to and from Norway between years 2003 and 2013. ${ }^{10}$ These data are confidential and provided by Statistics Norway (SSB). They are based on information from the customs declaration forms that firms are legally obliged to complete and submit. One declaration regards one shipment and is declared by the same actor, but may contain various transactions of different products (from different countries of origin in the case of imports). It contains information on the firm that trades (the owner of the product), the partner countries, the traded products and the declaration date. Importantly, it also contains information on the identity of the declarant, and thus on whether the trading firm handles the declaration itself or hires an intermediary - a broker- to do this. The data can be merged with firm-level balance-sheet data, also provided by the SSB, which i.a. contain information about the firms' sectoral affiliation. Since the intermediation model regards intermediary-use among producing firms, all analyses will be limited to trading produces in the manufacturing sector.

Table 1 shows all trade declarations by such firms, categorised according to trade mode (export/import) and declaration mode (self-declared/broker-handled). In line with the findings from the business literature reviewed in Sect. 2, it is evident that

\footnotetext{
Footnote 9 (continued)

the trading producers in the sample can be classified as merchant-users because all of them are registered as the exporter/importer in the customs declaration.

10 Raw oil and natural gas are excluded; further, a transaction must have a minimum value of $1000 \mathrm{NOK}$ $(122=$ USD in year 2018) to be included in the data.
} 
brokers play an important role in trade. Comparison of \# of declarations (column 1) and mean decl. value (column 2) between the two declaration modes, shows that two thirds of the export declarations as well as the value are broker-handled. In importing, even more trade is handled by brokers, $95 \%$ of the declarations and $92 \%$ of the value. This is similar to previous studies of merchant-intermediaries, which have found that these are more commonly used in importing than exporting (see footnote $5)$.

Comparison of the declaration values indicates that self-declared declarations are larger than broker-handled ones, and comparison of the mean and median values demonstrates that the distribution of declaration values is highly skewed, with many small declarations and a few large ones. This holds regardless of trade- and declaration mode.

The importance of brokers becomes even more prominent when we focus on producers and not single declarations. There are 17468 trading producers (exporters plus importers) in the sample, and while a declaration is either handled by a broker or self-declared, producers may switch between the two declaration modes in different declarations. In fact, almost no producers only self-declare in the course of all sample years. Some switch between self-declaring and hiring brokers even for the same country, product and year despite evidently possessing the equipment and knowledge necessary for self-declaring. A reason for this can be that producers do not always find it worthwhile to pay the fixed declaration-specific costs even though the product- and country level parts are already paid for (if the transaction is relatively unimportant, for instance). Another reason can be that the producer primarily demands other services than customs clearance - organisation of transport for instance, and that the broker bundles services with customs clearance being included in the sale, as discussed in Sect. 2.

The widespread use of customs brokers makes it reasonable to categorise the trading producers into two groups: self-declarants, which self-declare at least once during the sample period, and broker-users, which always use brokers. The last two columns of Table 1, demonstrate that the vast majority of producers belong to the latter group. Of all producers that trade in a given year, only $13 \%$ of the exporters and $10 \%$ of the importers are self-declarants (see \# of producer-year obs, column 4). Though not shown in the table, the data also reveal that even among the selfdeclarants, broker-use is more common than self-declaring. In exporting, the median self-declarant only handles one fifth of its trade value in a given year itself. The mean self-declarant handles $42 \%$, though. For importers, self-declaring is even less common; the median self-declarant lets brokers handle all its imports during a given year (but may self-declare in other years), whereas the mean share is about 0.15 .

In Sect. 2, we saw that previous surveys of nonrepresentative samples of firms indicated that customs clearance is often provided by freight forwarders or other logistics firms. The Norwegian data confirm this. There are in total 884 brokers serving the manufacturing producers, and for some $60 \%$ of them it is possible to obtain 
Table 2 Sectoral affiliation of customs brokers serving Norwegian manufacturing producers

\begin{tabular}{lllllllr}
\hline & $(1)$ & $(2)$ & $(3)$ & $(4)$ & $(5)$ & $(6)$ & $(7)$ \\
& $\begin{array}{l}\text { Freight } \\
\text { forwarder }\end{array}$ & $\begin{array}{l}\text { Other } \\
\text { logistics }\end{array}$ & Transport & $\begin{array}{l}\text { Manufac- } \\
\text { turing }\end{array}$ & $\begin{array}{l}\text { Wholesale/ } \\
\text { retail }\end{array}$ & Other & Total \\
\hline Value & 1292 & 163 & 145 & 72 & 4 & 64 & 1739 \\
\# brokers & 224 & 62 & 111 & 74 & 30 & 20 & 521 \\
\hline
\end{tabular}

Broker-handled trade (exports + imports) where information about the broker's sector affiliation is available, 2003-2013. Values are given in one billion (constant, year 2014) NOK. In the 2007 version of SSB's Standard Industrial Classification (SIC), which is based on NACE, the Other logistics category consists of all sub-categories in SIC 52 and 53, except for the sub-category 52.291, which is reserved for the Freight forwarder. The Transport category consists of 49-51, Manufacturing of 10-33 and Wholesale/retail of 45-47, except 45.2 and 45.403. In the 2002 version, the following applies: Freight forwarder $=63.401$, Other logistics $=$ all other sub-categories in 63 and 64, Transport $=60-62$, Manufacturing $=15-37$, Wholesale/retail $=50-52$, except 50.2 and 50.403 and 52.7. More information about SIC can be found at https://www.ssb.no/en/klass/klassifikasjoner/6 (accessed 11.06.2020)

information about the sectoral affiliation from SSB's balance-sheet data. ${ }^{11}$ Table 2 demonstrates that almost half of them are freight forwarders, and alone such companies clear three quarters of the trade value (exports plus imports) for which information on the sectoral affiliation of the broker exists. Other logistics companies and transporters are also of some importance, clearing slightly less than $10 \%$ of the value each. Most of these brokers operate in both exporting and importing.

Some companies from other sectors also provide customs clearance, but together these handle less than $10 \%$ of the value. Perhaps somewhat surprisingly, the most important sector among these is manufacturing. As many as $14 \%$ of the customs brokers in Table 2 are manufacturing producers that clear customs on behalf of other producers. They only account for $4 \%$ of the trade value, though. ${ }^{12}$

Some $6 \%$ of the brokers in Table 2 are wholesalers or retailers-the types of intermediary previously studied in the literature, but these clear a negligible share of the trade; less than $0.3 \%$. Such merchant-intermediaries are not the focus in this article, but it is worth mentioning that they themselves are common users of brokers. In exports, they are even more pronounced buyers of customs clearance services than the produces, self-declaring less than $20 \%$ of their declarations. In imports the $\%$ of self-declared declarations is about the same for merchants and produces: $5 \%$. Furthermore, freight forwarders are the most frequent type of broker used, accounting for $62 \%$ of the merchants' broker-handled trade were information about the broker's sectoral affiliation exists. Other companies in logistics and transport account for an additional $33 \%$, whereas manufacturing producers account for less than $1 \%$ and other wholesalers/retailers for less than $4 \%$. These figures indicate that merchants do

\footnotetext{
11 These brokers also cover about $60 \%$ of the broker-handled trade (in terms of value as well as number of declarations).

12 Also other scholars have found that certain producers perform trade-related services for other producers. Bernard et al. (2018) demonstrate that many Belgian manufacturers export products they do not produce, so-called Carry-Along Trade (CAT). However, the extent of CAT seems to be much larger than the extent of producers clearing customs for other produces; among the Belgian firms a whole $30 \%$ of the export value was CAT.
} 
Table 3 Characteristics of trading producers and customs brokers

\begin{tabular}{|c|c|c|c|c|c|c|c|c|}
\hline & \multicolumn{2}{|l|}{ (1) } & \multicolumn{2}{|l|}{ (2) } & \multicolumn{2}{|l|}{ (3) } & \multicolumn{2}{|l|}{ (4) } \\
\hline & \multirow{2}{*}{\multicolumn{2}{|c|}{ Producers }} & \multicolumn{4}{|c|}{ Subgroups of producers that } & \multirow{2}{*}{\multicolumn{2}{|c|}{ Brokers }} \\
\hline & & & \multicolumn{2}{|c|}{ Self-declare } & \multicolumn{2}{|c|}{ Use brokers } & & \\
\hline & Mean & Median & Mean & Median & Mean & Median & Mean & Median \\
\hline \multicolumn{9}{|l|}{ Exporters } \\
\hline Trade value & 56.71 & 0.503 & 228.8 & 14.42 & 29.94 & 0.352 & 336.7 & 54.87 \\
\hline \# of partner countries & 6.596 & 2.000 & 14.85 & 8.000 & 5.311 & 2.000 & 20.55 & 13.00 \\
\hline \# of different products (HS6) & 9.114 & 3.000 & 17.02 & 8.000 & 7.885 & 3.000 & 70.79 & 24.00 \\
\hline \# of different products (aggr.) & 2.506 & 2.000 & 3.709 & 3.000 & 2.319 & 2.000 & 7.817 & 77.000 \\
\hline$\#$ of firms used/served & 4.887 & 2.000 & 7.975 & 4.000 & 4.406 & 2.000 & 44.05 & 12.00 \\
\hline \multicolumn{9}{|l|}{ Importers } \\
\hline Trade value & 19.05 & 0.243 & 99.61 & 5.684 & 9.764 & 0.193 & 319.3 & 62.04 \\
\hline \# of partner countries & 4.894 & 3.000 & 9.766 & 7.000 & 4.333 & 2.000 & 17.67 & 13.00 \\
\hline \# of different products (HS6) & 15.39 & 5.000 & 41.57 & 19.00 & 12.38 & 4.000 & 153.1 & 52.00 \\
\hline \# of different products (aggr.) & 3.500 & 2.000 & 5.979 & 5.000 & 3.215 & 2.000 & \multicolumn{2}{|c|}{9.87711 .00} \\
\hline \# of firms used/served & 7.186 & 3.000 & 15.90 & 11.00 & 6.182 & 3.000 & 131.1 & 24.00 \\
\hline
\end{tabular}

Trade by Norwegian manufacturing producers, 2003-2013. Figures are means and medians for all producer-year observations. Self-declarants may also use brokers, whereas broker-users never self-declare during the period. Trade value is given in million constant (year 2014) NOK. \# of different products are reported for two different levels of aggregation. Hs6 refers to 6-digit product categories in the Harmonised System; aggr. refers to the 21 main chapters in the customs tariffs (2002 versions in both cases). \# of firms used/served refers to the number of brokers used for the producers, and the number of producers served for the brokers

not to handle customs clearing to any significant extent, neither for themselves nor for others.

Table 1 showed that declarations handled by broker-intermediaries were smaller than those handled by producers. An interesting question is whether this translates into differences in aggregated trade handled by the intermediaries (brokers) and the two types of produces; those that rely on the intermediaries (broker-users) and those that don't (self-declarants). Studies of merchant-intermediaries have only been able to assess this question by either comparing the intermediary (the merchant) to the direct trading producer, as in the intermediary approach; or the direct trading producer to the merchant-user, as in the intermediary-user approach. The data used here, in contrast, allow for comparison of all three actors at the same time. Table 3 shows their mean and median annual traded value. In addition, it shows their country- and product scopes; the latter both for disaggregated product categories, classified according to the 6-digit Harmonised System [henceforth: HS6], and for aggregated ones, classified according to the 21 main chapters in the customs tariffs, where each category represents quite distinct products, for example, Manufactured food, Textiles and Chemicals. 
The table clearly demonstrates that self-declarants trade much more than brokerusers, the median traded value being 30-40 times greater for the former. They trade with more countries and in more products, and also in a greater variety of products. Brokers in turn, score higher on all these measures than the self-declarants. The table also reveals that brokers pool trade from several different produces. As can be seen from the last row in each subpanel, the median broker serves, respectively, 12 and 24 different produces in exporting and importing during one year, and the mean broker serves considerably more. The producers, in turn, tend to stick to only a few brokers. Admittedly, the self-declarants use a higher number of brokers than the broker-users, but this is not surprising as they trade in far more countries and products.

From Table 3 it is also clear that the mean values are generally much greater than the median values, indicating highly skewed distributions of producers and brokers. The majority of both actors handle small values in a few countries and products, and the major part of trade is accounted for by a few large actors. In fact, the top $10 \%$ of all produces (in terms of trade value) account for $76 \%$ of all trade (exports + imports). The same holds for brokers, where the top $10 \%$ account for $71 \%$ of all broker-handled trade. Above, we saw similar patters at the declaration level. For trading producers, these findings are in accordance with previous studies by e.g. Bernard et al. (2012), which show that most firms participating in trade generally account for low trade values, whereas a small group of firms account for the major part of trade. Similar findings have also been reported for merchant-intermediaries by e.g. Blum et al. (2018), but to my knowledge, this is the first article that documents a pattern like this for customs brokers. ${ }^{13}$

\section{Econometric analyses}

\subsection{Trade by brokers, self-declarants and broker-users}

In accordance with the intermediation model, the descriptive statistics presented in Table 3 suggested a sorting pattern where broker-users trade smaller values than self-declarants. Self-declarants, in turn, trade smaller values than brokers, and each broker serves several producers. This is in accordance with brokers being better able at overcoming fixed customs clearing costs by pooling trade from many producers. The descriptives also suggested that broker-users are more specialised than the selfdeclarants as regards countries and products, and that self-declarants are more specialised than brokers. However, this may not hold if we control for differences in the traded value. Similarly to how Bernard et al. (2010) compared merchants to direct trading producers, I pool together brokers and producers during all sample years and

\footnotetext{
13 Table 3 also shows large differences in trade values between producers that export and import. The median value of the former is almost twice as high as for the latter. Brokers, in contrast, handle similar values of imports and exports.
} 
regress their trade value as well as country- and product scopes on an indicator variable for brokers. In contrast to Bernard et al. (2010) however, I can also study the intermediary-users; this is done by including an additional indicator for self-declarants among the independent variables (broker-users being the base category). Also included among the independent variables are the trade value (in the scope regressions only), and dummies for years and main aggregated product traded. Equality between the values of the coefficients for brokers and self-declarants is tested using a Wald test.

Table 4 shows the results, and the patterns of trade values are still evident. The estimated coefficients for brokers (column 1) as well as for self-declarants (column 2) are significantly positive, and those for the former are larger and significantly different than those for the latter (column 3). This holds for exporting and importing alike. ${ }^{14}$ The regressions also show that when conditioning upon trade value, the higher degree of specialisation among self-declarants relative to brokers suggested by the descriptives no longer applies, except for in exported products. In importing, the converse is true; self-declarants have wider scopes in both countries and products than brokers (and the brokers do not have significantly larger scopes than the broker-users). ${ }^{15}$ This may suggest that brokers build competence on importing certain products from certain countries, and this may put them in a better position to offer reduced fixed trade costs for producers that hire their services. The behaviour of the producers in turn, is likely to be more dependent on the products they produce and the inputs they use, and they may therefore be more concerned with selling and buying in the currently best suited markets rather than specialising their market-specific customs clearing competence. This dependency may also be a likely explanation for the producers' relative narrower product scope in exporting than importing if the variety of goods a producer makes is smaller than the inputs it uses. The results further show that producers that self-declare still have wider countryand product scopes than those that use brokers, with one exception; self-declarants export a smaller number of products, also relative to broker-users. This is similar to what McCann (2013) found comparing merchant-users to direct trading produces. It may indicate that for producers, product-specific fixed costs of clearing customs in exporting more than cancel out any economies of scope. ${ }^{16}$

\footnotetext{
14 Similarly, studies of merchant-users showed that these traded smaller values than direct trading produces (Abel-Koch 2013; McCann 2013; Grazzi and Tomasi 2016; Ahn et al. 2011). Furthermore, some studies comparing direct trading producers to merchants found that the latter traded larger values than the former (Ahn et al. 2011; Bernard et al. 2015). The literature is ambiguous on this point, however. Bernard et al. (2010), Akerman (2018) and Blum et al. (2018) all found the converse, and Utar (2017) found different results for importing and exporting; merchants traded smaller values than direct trading producers in exporting, but larger ones in importing.

15 Similar results for product scope in exporting was found for merchant-intermediaries by Bernard et al. (2010), Ahn et al. (2011) and Akerman (2018). They showed that (conditional upon firm size) wholesalers had a wider product scope than direct trading producers. Furthermore, similar to what was found here for country scope, Bernard et al. (2010) showed that wholesalers had a narrower country scope than direct trading producers in importing, but not in exporting. Ahn et al. (2011) and Akerman (2018) reached similar conclusions for exporters, though.

16 To my knowledge, there are no studies documenting differences in country scope between direct trading produces and merchants-user.
} 


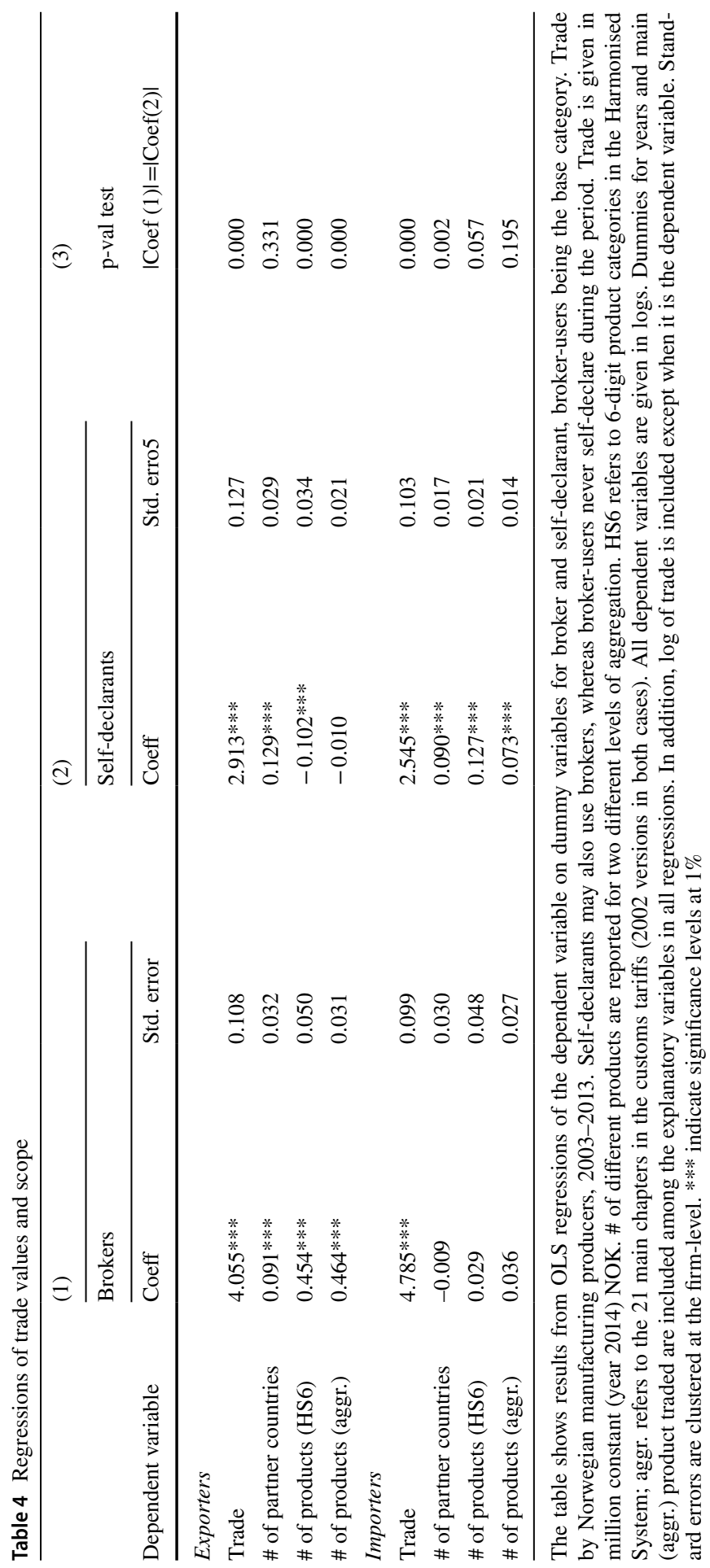




\subsection{The choice of self-declaring vs. using brokers}

\subsubsection{Declaration level}

Above, I have argued that brokers are better able at overcoming fixed costs of clearing customs than producers, and possibly also face lower costs like that. I now turn to studying whether a producer's choice of self-declaring rather than using brokers is related to its trade value and hence ability to pay the fixed cost, as the intermediation model predicts when applied to brokers. As mentioned, at least parts of such costs are likely to accrue at the shipment level, as a separate declaration form must be completed for each shipment. Consequently, there should be an incentive for producers to self-declare when the shipment is large in value and to hire brokers when it is small. Indeed, this is what the descriptive statistics in Table 1 suggested. To more formally test this, I regress an indicator variable for self-declaring on the value declared using a probit model, where year dummies are included as controls. The average partial effects (APEs) are presented in Table 5 and confirm that the probability of self-declaring increases with shipment value, in exports as well as import. A $10 \%$ increase in the value is associated with an increase in the probability of selfdeclaring by 0.25 per cent points for exporters and 0.13 per cent points for importers. Evaluated relative to the share of declarations that are self-declared, which are $33.7 \%$ for exporters and $4.9 \%$ for importers (see Table 1), this implies that the probability of self-declaring increases by, respectively, $0.75 \%$ for exporters and $2.67 \%$ for importers when the shipment value increases by $10 \%$.

\subsubsection{Producer-country-product-year level}

There is a chance that the correlations found in the previous section are spurious. Due to computational constraints, it was not possible to include other controls than year dummies in the regressions, but features of producers, countries and products are likely to have an influence. To better assess the effect of trade value on choice of declaration mode, I aggregate the data and calculate the share of trade from producer $i$ to/from country $j$ of product $v$ in year $t$ that is traded without using intermediaries, i.e. the share that is self-declared $\left(S h S D_{i j v t}\right)$. This variable is then used as dependent variable in estimation of the following equation:

$$
S h S D_{i j v t}=\alpha+\boldsymbol{\beta} \mathbf{x}_{\mathbf{i j v t}}+c_{i j v}+\eta_{t}+\varepsilon_{i j v t}
$$

$\alpha$ and $\boldsymbol{\beta}$ are coefficients to be estimated, $\eta_{t}$ is a year dummy and $\varepsilon_{i j v t}$ is noise distributed as Normal[0, $\left.\sigma_{\varepsilon}{ }^{2}\right] . \mathbf{x}_{\mathbf{i j v t}}$ is a vector of explanatory variables of which the main variable of interest is Trade $_{i j v t}$; producer $i$ 's trade in country $j$ in product $v$ (at the HS6 level) in year $t$. In the intermediation model, Trade $e_{i j v t}$ is proportional to the producer's operating profits in market $j v$ and should therefore control for that. However, this may not hold in reality, and $\mathbf{x}_{\mathbf{i j v t}}$ therefore also contains a number of other attributes of the producer, country and product that are likely to affect market specific profitability or for some other reason may affect the inclination to self-declare. These include the producer's size in terms of number of employees $\left(\mathrm{NoEmp}_{i t}\right)$ and 
Table 5 Regression of probability of self-declaring on the value declared (shipment value)

\begin{tabular}{|c|c|c|c|c|}
\hline & \multirow{2}{*}{$\frac{\text { Exporters }}{\text { APE }}$} & \multirow[b]{2}{*}{ Std. error } & \multicolumn{2}{|l|}{ Importers } \\
\hline & & & APE & Std. error \\
\hline Shipment value & $0.025 * *$ & 0.011 & $0.013 * * *$ & 0.002 \\
\hline \# obs & $6,127,946$ & & $6,575,156$ & \\
\hline \# clusters (produces) & 8690 & & 14,438 & \\
\hline Log pseudolikelihood & $-3,891,667$ & & $-1,238,170$ & \\
\hline
\end{tabular}

Trade by Norwegian manufacturing producers, 2003-2013. Values in log. Year dummies are included and standard errors are clustered at the level of the producer

$*, * *, * * *$ indicate significance levels at, respectively, $10 \%, 5 \%$ and $1 \%$

labour productivity $\left(\operatorname{Prod}_{i t}\right)$; an indicator variable for foreign ownership $\left(\mathrm{ForOwn}_{i t}\right)$; market-size in terms of partner country's GDP $\left(G D P_{j t}\right)$; partner country's remoteness $\left(\operatorname{Rem}_{j t}\right)$; and trade costs, reflected in an indicator variable for free trade agreement with country $j\left(F T A_{j t}\right)$ in addition to country specific tariffs on product $v$ (Tariff $f_{j v t}$ ). Furthermore, to account for the fact that different parts of the fixed customs clearing costs may accrue at different levels - shipment, country, product, and for possible interdependencies between market specific trade decisions as discussed in Sect. 2, $\mathbf{x}_{\mathbf{i j v t}}$ also includes the producer's total number of declarations $\left(\mathrm{NoDecl}_{i t}\right)$, partner countries $\left(\mathrm{NoCo}_{i t}\right)$ and traded products $\left(\mathrm{NoPr}_{i t}\right)$. Not only observed, but also unobserved characteristics are likely to affect intermediary-use. For example, there may be some underlying productivity differences at the producer-country-product level, not captured by the control variables mentioned. The panel dimension of the data allows for controlling for such differences when they are time invariant - they are captured by $c_{i j v}$. How $c_{i j v}$ is controlled for is described in Sect. 4.2.2.1, but it involves including as additional controls a number of auxiliary variables, which are listed in the notes to Table 6a and $\mathrm{b}$ in Sect. 4.2.2.2.

Equivalently to most studies using the intermediary approach, this design implies studying how the share of trade accounted for by intermediaries to/from a given market is associated with features of that market. But, in contrast to those studies, the share is here calculated for each producer rather than at the more aggregated level, which permits controlling for producer attributes as in the intermediary-user approach. Consequently, the strengths from both approaches are combined.

Data for producer features are taken from SSB's balance-sheet data, and data for market characteristics (country and product) are taken from various publicly available sources. Table 7 in the Appendix provides more details on the regression variables, including summary statistics and source information. Observations where any element in $\mathbf{x}_{\mathbf{i j v t}}$ is missing are excluded from the analysis. For the export data, this leads a loss of $26 \%$ of all observations, covering about $19 \%$ of all exports; whereas for the import data, $13 \%$ of all observations, covering $12 \%$ of all imports are lost.

4.2.2.1 Econometric issues There are a number of issues that has to be dealt with when estimating Eq. (1). Firstly, the dependent variable is a share including a considerable amount of $0 \mathrm{~s}$ (see Table 7 in the Appendix). Ahn et al. (2011), Crozet et al. (2013) and Akerman (2018) dropped observations like that and applied linear 
estimation methods. However, dropping such observations may lead to selection bias, and linear estimation may lead to specification bias-both potentially important issues in the present case due to the large prevalence of $0 \mathrm{~s}$. Therefore, I apply a fractional probit estimation model.

Secondly, the $c_{i j}$,'s cannot be appropriately controlled for by using conventional panel data methods like fixed or random effects. Including fixed effects in the fractional probit model yields biased coefficients estimates when there are relatively few time periods like here, due to the incidental parameters problem (Neyman and Scott 1948). Furthermore, the $c_{i j v}$ 's are likely to be correlated with elements in $\mathbf{x}_{\mathbf{i j v t}}$. For example, unobserved productivity differences (captured by $c_{i j v}$ ) are likely to be correlated with the producer's size (included in $\mathbf{x}_{\mathbf{i j v t}}$ ) as more productive producers are also likely to be larger. Consequently, random effects will also yield biased estimates.

Thirdly, the panel is unbalanced; each producer-country-product combination may appear for a different number of years, and selection into the sample is also likely to be correlated with $c_{i j v}$. For example, if a producer has employees well experienced in international commerce, it is likely to trade in more countries and products for longer time periods.

To deal with these issues, I apply a correlated random effects fractional probit model for unbalanced panels (henceforth: CRE fprobit), suggested by Wooldridge (2019). Let $s_{i j v t}$ be equal to 1 if producer-country-product combination $i j v$ appears in year $t$ (and 0 otherwise) and $T_{i j v}$ be the number of sample years the combination appears: $T_{\mathrm{ijv}}=\sum_{t=1}^{T} s_{i j v t}$ (where $T$ is the total number of sample years in the whole panel). Furthermore, let $g_{i v j r}$ be an indicator variable for sample selection: $g_{i j v r}=1\left[T_{i j v}=r\right]$ where $\mathrm{r}$ goes from 1 to $T$. In other words, there are $T$ different $g_{i v j r}$, each reflecting a specific number of time periods it is possible for a combination to appear in the sample. The method implies specifying a distribution of the firm-country-product specific effect $-c_{i j v}$-conditional on all the explanatory variables $-\mathbf{x}_{\mathbf{i j v t}}-$ and appearance in the sample $-s_{i j v t}$. Specifically, it is assumed that this distribution is Normal with conditional expectation depending on time-averages of each element of $\mathbf{x}_{\mathbf{i j v t}}$ denoted $\overline{\mathbf{x}}_{\mathbf{i j v}}$, and the indicator variables for sample selection: $E\left[c_{i j v} \mid s_{i j v t}, s_{i j v t} \mathrm{x}_{\mathrm{ijvt}}\right] \stackrel{\mathrm{x}}{=} \sum_{r=1}^{T}\left(\psi_{r} g_{i j v r}+g_{i j v r} \overline{\mathrm{x}}_{i j v} \xi_{\mathrm{r}}\right)$, for $t=1, \ldots, T$. Furthermore, the conditional variance of $c_{i j v}$ also depends on sample selection: $\operatorname{Var}\left[c_{i j v} \mid s_{i j v t}, s_{i j v t} \mathrm{x}_{\mathrm{ijvt}}\right]=\exp \left(\tau+\sum_{r=1}^{T-1} g_{i j v r} \omega_{r}\right)$. The sum in the variance goes to $T-1$ because the group of observations appearing in all years $(T)$ is the base group. $\tau$ is the variance of this group, and the $\omega_{r}$ 's are the deviations from $\tau$ for each $r$. In other words, together $\tau$ and the $\omega_{r}$ 's denote all the variances (one variance for each number of years a combination may appear in the sample). Assuming that all the elements of $\mathbf{x}_{\mathbf{i j v t}}$ are strictly exogenous (conditional on $c_{i j v}$ ), and that the $s_{i j v t}$ 's are independent of the $\varepsilon_{i j t}$, ${ }^{17}$ Eq. (1) can now be estimated by replacing $\mathrm{c}_{i j v}$ with:

$$
c_{i j v}=\boldsymbol{\xi}\left(\overline{\mathbf{x}}_{\mathbf{i j v}}, \ldots, \overline{\mathbf{x}}_{\mathbf{i j v}}\right)+\left(g_{i j v 3}, \ldots, g_{i j v T}\right)
$$

\footnotetext{
17 This implies assuming that any shock to the self-declared share of trade in one year does not affect being in the sample in other years, which seems fairly plausible. Note that the same assumption is made in linear fixed effects models when the panel is unbalanced.
} 
$\begin{array}{llll}n & n & 0 & \infty \\ 0 & 0 & 0 & 0 \\ 0 & 0 & 0 & 0\end{array}$

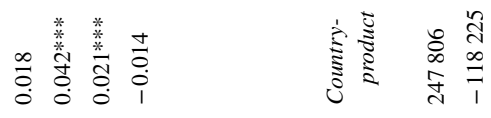

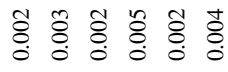

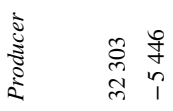

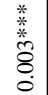

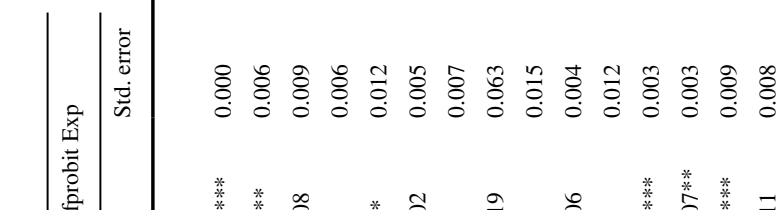

\&̊

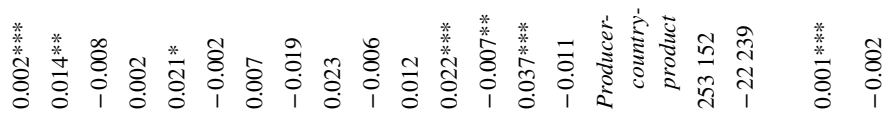

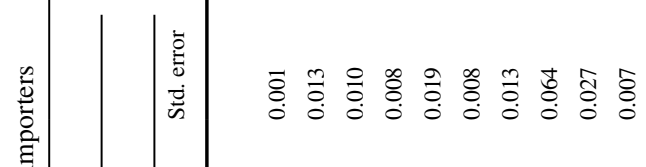

ஓ्ष

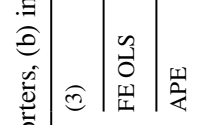

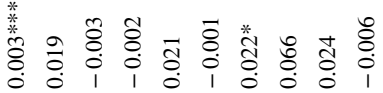

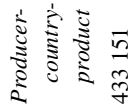

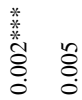

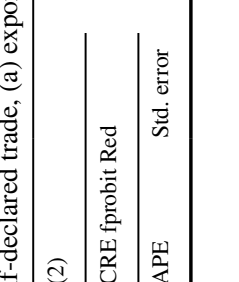

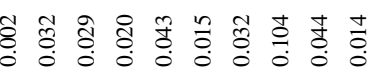

$\stackrel{\Xi}{\circ} \stackrel{+}{\circ}$

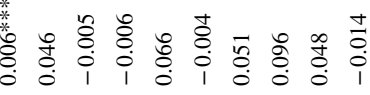

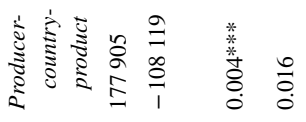

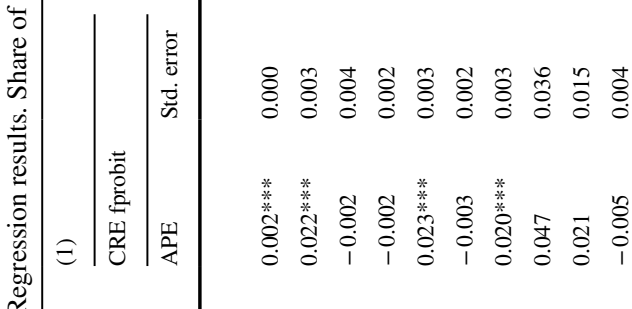

$\begin{array}{ll}8 & + \\ 0 & 0 \\ 0 & 0\end{array}$

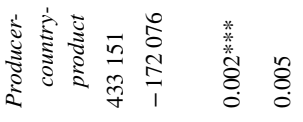

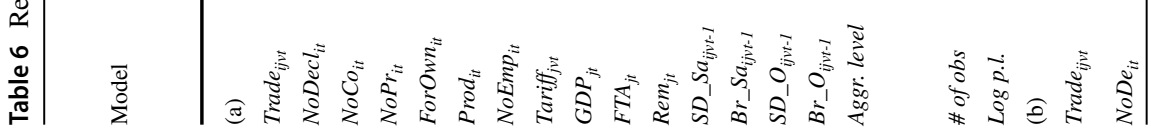




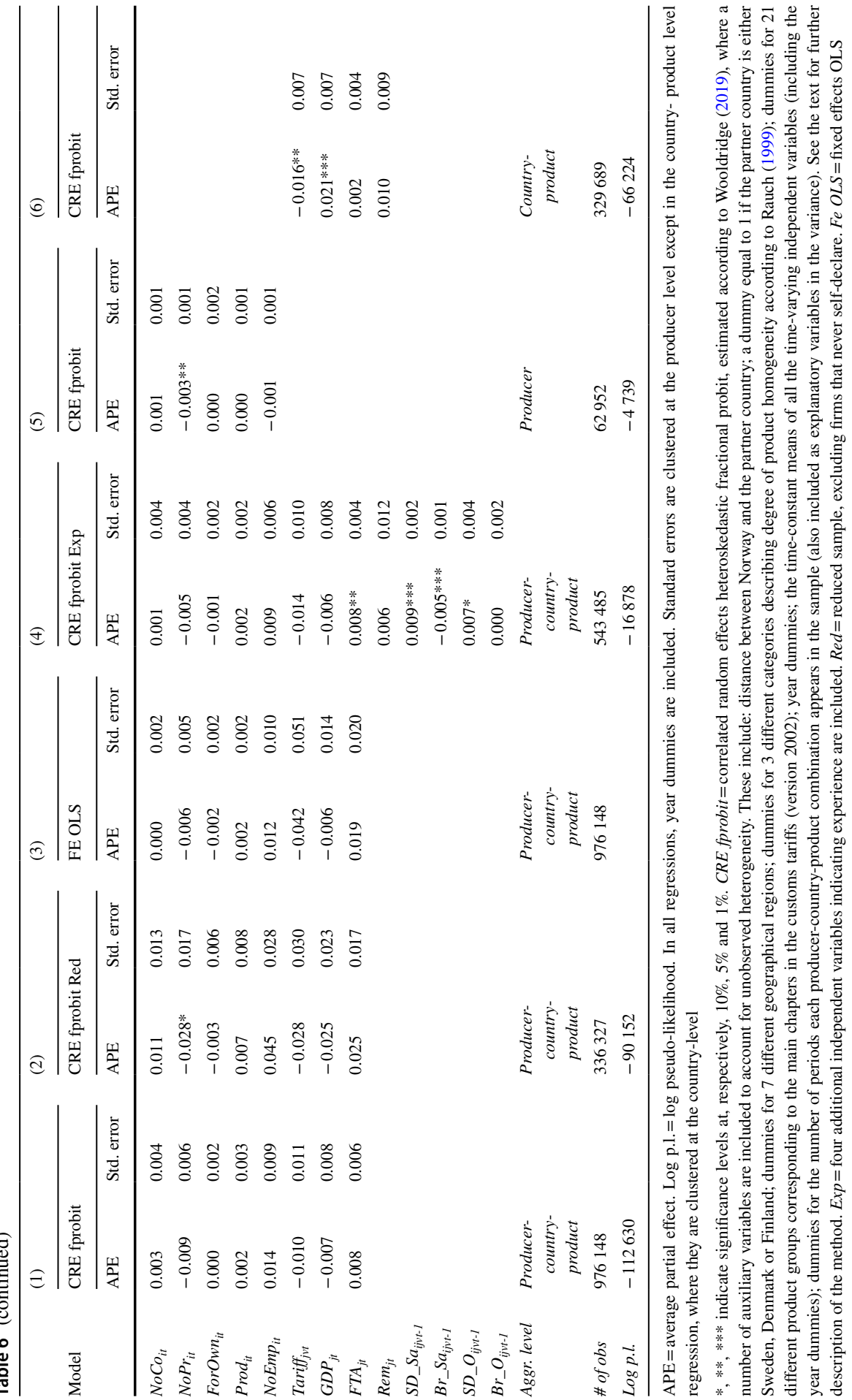


and applying a heteroskedastic fractional probit model with the indicator variables $\left(g_{i j v 3}, \ldots, g_{i j v T-1}\right)$ as explanatory variables in the variance. This accounts for the fact that the variance varies according to the unbalancedness of the sample.

The method yields estimates of the $\beta$ 's scaled by a positive factor, which again can be used directly to calculate the APEs of the elements of $\mathbf{x}_{\mathbf{i j v t}}$. However, the (scaled) coefficients are only identified when there is some time variation in $\mathbf{x}_{\mathbf{i j v t}}$, otherwise $\mathbf{x}_{\mathbf{i j v t}}$ and $\overline{\mathbf{x}}_{\mathbf{i j v}}$ will be perfectly collinear. As a consequence, all observations that appear only once during the sample years must be dropped, which is the reason why neither $g_{i v j 1}$ nor $g_{i j v 2}$ are included in Eq. (2) (the latter being the base group). ${ }^{18}$ Furthermore, while time constant explanatory variables (like distance to country $j$ ) can be included in (1), it is not possible to separate their partial effect on $S h S D_{i j v t}$ from their partial correlation with $c_{i j v t}$. Estimated effects of variables like that are therefore not reported below, nor are those of the elements in $\overline{\mathbf{x}}_{\mathbf{i j \mathbf { v }}}$.

The CRE fprobit model resembles a fixed effects model in that it allows for correlation between $c_{i j v}$ and the explanatory variables. The estimated $\beta$ 's therefore, to a large degree, reflect the effect of changes within each producer-country-product combination over time (in contrast to differences between combinations). In fact, Wooldridge (2019) points out that estimating Eq. (1) with $c_{i j v}$ given by Eq. (2) using OLS is equivalent to a linear fixed effects model (i.e. a within model). But, unlike the $C R E$ fprobit model, the linear model makes no assumptions about the distribution of $c_{i j v}$. As a robustness check, I also estimate a model like that.

Also see Wooldridge (2005) and Papke and Wooldridge (2008) for, respectively, dichotomous and fractional dependent variable balanced-panel CRE models, and Bluhm (2013) for additional explanations of the Wooldridge (2019) method. ${ }^{19}$

4.2.2.2 Results The results are reported in Table $6 \mathrm{a}$ and $\mathrm{b}$. To be able to compare the estimates between exporters and importers and also among different models, APEs rather coefficients are displayed. The results from the main estimation (column 1) clearly demonstrate a positive association between the self-declared share of a producer's trade to a given market and the traded value. Hence, the tendency of larger trade values being self-declared and smaller ones being handled by brokers found in Sect. 4.2.1 also holds when controlling for observed and unobserved factors at the producer, country and product level. This indicates that the model of intermediation is not only relevant in the context of merchant-intermediaries, but also in the context of broker-intermediaries. Furthermore, the results are similar for exporters and importers, suggesting that customs brokers facilitate both modes of trade.

For exporters, the APE for $\mathrm{NoDecl}_{i t}$ is positive and significant. A plausible interpretation is that any negative influence from larger fixed costs due to more shipments are cancelled out by a positive influence of economies of scope in the number of declarations. For importers, the APE for NoDecl $_{i t}$ is not significant, however.

\footnotetext{
18 This leads to an additional drop in the number of observations of about $30 \%$ for exporters and importers alike, covering about $3 \%$ of all exports and $5 \%$ of all imports.

19 Note that year dummies are included in $\bar{x}_{\mathrm{ijv}}$. Due to the unbalancedness of the panel, the means of the year dummies may differ for different $i j v$ combinations. Unlike in the balanced CRE fractional probit model, these means are therefore included in $\overline{\mathrm{x}}_{\mathrm{ijv}}$.
} 
Country and product scope also do not seem to influence much, neither in exporting nor in importing. Regarding other controls, for exporters the APE for $N o E m p l_{i t}$ is positive and significant, which is in line with predictions from the intermediation model. Furthermore, the APE for ForO $w_{i t}$ is significantly positive, and a reason for this might be that foreign owners, by bringing capital and knowledge, increase the producer's ability to pay the fixed costs required for being able to self-declare. No other controls are found to be significantly associated with the share of self-declared trade, neither for exporters nor importers. Also note that the results for variables other than Trade $_{i j v t}$ are not robust to alternative model specifications.

The estimated APEs for Trade $i j v t$ are moderate in size, indicating that a $10 \%$ increase in a producer's market specific traded value increases its predicted $\%$ of selfdeclared trade to that market by 0.023 percentage points for exporters and 0.016 percentage points for importers. The average \% of a producer's self-declared trade in a given market is $20.3 \%$ for exporters and 3.2\% for importers (see Table 7 in the Appendix), and evaluated relative to this, the APEs indicate that the probability of self-declaring increases by $0.16 \%$ for exporters and $0.17 \%$ for importers when the market specific traded value increases by $10 \%$. For exporters, the estimated effect of trade value is moderate relative to that of producer-size, which is about 10 times larger. The moderately sized effects are not surprising given that many producers never self-declare during the course of all sample years they trade, resulting in a large share of the $S h S D_{i j v t}$ observations being equal to 0 (see the last two rows of Table 7 in the Appendix). To check how the results are influenced by this large group of producers, I run the CRE fprobit estimation on a reduced sample where they are dropped (CRE fprobit Red). As can be seen in the second columns of Table 6a and b, the APEs for trade value have the same sign as those in the full sample, but the sizes are larger. The APE for exporters have tripled and that for importers have more than doubled.

To check how sensitive the results are to the assumptions about the correlation structure between the explanatory variables and $c_{i j}$, I also estimate Eq. (1) using a linear fixed effects model $(F E O L S)$ ). The results, displayed in the third columns of Table $6 \mathrm{a}$ and b, are similar to those from the main model; the estimated effects from Trade ${ }_{i j v t}$ are still significantly positive, and their economic significance is also similar. This may indicate that any bias from misspecification of the correlation structure is not severe in the main model.

In the main model, it was assumed that a producer's customs clearing experience didn't affect its current declaration modes. However, experience from self-declaring is likely to reduce the current cost of self-declaring, because producers that have selfdeclared in previous years have already familiarised themselves with the relevant procedures and regulations. If this holds, the share of self-declared trade of experienced self-declarants is likely to increase or maintain from one year to another. Similarly, experience from using brokers may affect current broker-use if procedures related to the purchase of brokerage services have to be learnt. However, if the fixed costs of self-declaring are larger than those for broker-use, and experience leads to a larger decline in the former than in the latter, experience will matter more for self-declaring.

To check for effects like these, I run the main estimation again, adding to the independent variables dummies for, respectively, having self-declared and used brokers for at least one trade transaction with market $j v$ in year $t-1\left(S D \_S a_{i j v t-1}\right.$ and $\left.B r \_S a_{i j v t-1}\right)$. Both 
dummy variables may be positive at the same time, as the producer may have used brokers for some transactions and self-declared others. Experience in other markets may also affect declaration mode, as procedures can be similar; and thus, I include two additional dummy variables for experience like that $\left(S D_{-} O_{i j v t-1}\right.$ and $\left.\mathrm{Br} \_O_{j v t-1}\right)$. Significantly positive APEs for the $S D$ variables indicate that experience matters for self-declaring, whereas significantly negative APEs for the $\mathrm{Br}$ variables indicate that it matters for broker-use.

The results, displayed in the fourth columns of Table $6 a$ and $b$, clearly indicate that experience in the same market matters for both modes of declaration. ${ }^{20} \mathrm{How}$ ever, the absolute values of the estimated effects are significantly larger for selfdeclaring than for broker-use (at the $1 \%$ level at least). With regards to experience in other markets, only the estimated effect from $S D_{-} O_{i j v t-1}$ are significant. Consequently, experience seems to matter more for self-declaring than broker-use, as expected. The estimated effects from trade value are still positive and significant, and hence, the result from the main analysis holds.

A few other studies analysed how experience mattered for intermediary-use in the context of merchants. McCann (2013) found that persistence in exports was larger for producers trading directly rather than via merchants, and in an analysis supplementary to that of China, Ahn et al. (2011) found that Ghanaian firms were more likely to export directly if they had previously exported via a merchant. Furthermore, Bai et al. (2017) found that sunk (as well as fixed) costs were larger when exporting directly than through a merchant, but that the direct exporters improved their performance more (so-called 'learning by exporting').

The lack of influence from variables at the market level in the analyses contrasts findings in studies of merchant-intermediaries, which generally found that market features were important. However, those analyses were done at more aggregated levels than here. To check whether analysing my data at higher aggregation levels would influence the results, I perform two additional analyses. Firstly at the producer level, as in the intermediary-user approach; and secondly at the market level, as in the intermediary approach. These regressions are estimated with $C R E$ fprobit as in the main model, using as dependent variables, respectively, the self-declared share of producer $i$ 's total exports or imports; and the self-declared share of total exports and imports to/from market $j v$. In both regressions, independent variables at finer aggregation levels than the dependent variable are dropped. ${ }^{21}$ To some extent, the results from these estimations diverge from those from the main model. In the regressions at the producer level (columns 5), the APE for declaration scope is significantly positive for both exporters and importers, whereas in the main model it is only significant for exporters. Furthermore, in contrast to the main model, the APE for product scope is significantly negative for

\footnotetext{
${ }^{20}$ Note that in these regressions, only producer-country-product observations with trade in at least two consecutive periods are included, as information on lagged declaration mode are only available for observations like that. Thus, the sample size is smaller than in the main analysis.

21 This implies that the regressions do not contain any variable reflecting the traded value. This is equivalent to the regressions carried out in Ahn et al. (2011), Crozet et al. (2013) and Akerman (2018) studying the share of exports accounted for by merchants using the intermediary approach. Studies applying the intermediary-user approach sometimes include a variable for total sales (domestic and foreign), but, like here, the number of employees is often used as a measure of firm size instead.
} 
both modes of trade, and that for country scope is positive for exporters. For exporters, the APE for firm size is also significantly positive as in the main model, but that for foreign ownership is not. The regressions at the market level (columns 6), in turn, yield significant APEs for several country- and product specific characteristics, including positive APEs for $\mathrm{GDP}_{j t}$ for exporters as well as importers. Also trade costs matters $-F T A_{j t}$ influences positively on the share of self-declared exports, and Tariff ${ }_{i v t}$ influences negatively on the share of self-declared imports. These results demonstrate that market specific effects are only significant when each produces' market specific profitability from trade are not controlled for.

\section{Concluding remarks}

This study has focused on customs brokers, a type of intermediary in international trade rarely examined in economics. Recent research has suggested that merchant-intermediaries like wholesalers facilitate trade by offering the opportunity of reducing fixed trade costs for firms that use them. As a result, firms with small trade values will use intermediaries, whereas firms that trade a lot or increase their trade above a certain threshold will manage without them. I have found indications of a similar role for customs brokers.

This study draws on an exhaustive panel of the trade transactions of Norwegian manufacturing producers, with information on the use of brokers. The data reveal that the vast majority of producers participating in international trade engage brokers to clear their goods through customs rather than self-declare. Brokers handle larger trade values than producers do, and producers that self-declare trade more than those that rely solely on brokers.

The tendency of producers self-declaring large trade values was further confirmed in econometric analyses where observed and unobserved characteristics of produces, countries and products combined where controlled for. These showed that the share of trade from a given producer in a given market that was self-declared was positively associated with the producer's market specific trade value - a result that was very robust to alternative model specifications. Apart from trade value, however, few other variables were found to significantly affect broker-use consistently across different model specifications. The only exception was perhaps producer size for exporters.

The lack of influence from country- and product characteristics contrasts empirical studies of merchant-intermediaries studying the share of trade accounted for by wholesalers, which generally found that this was significantly correlated with variables like GDP and tariffs. However, these studies did not control for producer-specific characteristics. Nor did they control for the trade value or other observed and unobserved characteristics at the producer, country and product level combined. The results presented here may indicate that controlling for such variables is important.

The results are consistent with customs brokers offering an opportunity for producers to avoid paying fixed customs clearing costs by purchasing customs clearing services for a variable fee. They are probably also consistent with brokers offering reductions of 
other types of fixed trading cost related to organisation of transport because the brokers operate in logistics sectors where bundling of services is very common. Without the possibility of hiring brokers, some of the broker-users might not have been able to handle customs clearing or other logistical challenges in certain markets, or even participate in international trade at all. Hence, customs brokers are intermediaries that seem to facilitate trade in the manner described in Ahn et al. (2011) and similar models. The results are similar for exporters and importers, suggesting that the trade facilitating role of broker-intermediaries is not only important in exporting, but also in importing.

Whereas policymakers concerned with international market participation often emphasise ensuring sound business conditions for producing firms, the results presented here indicate that having well-functioning intermediary sectors is also highly relevant. Furthermore, it can be important to continue efforts aimed at streamlining and simplifying customs procedures, also in a highly developed country like Norway, in order to reduce fixed costs of exporting and importing.

Not only customs brokers and merchants, but also other types of intermediaries, like transporters and marketing agents, may be crucial for producers' ability to sell and buy in international markets. Future research should study the facilitating role of these. Another important theme is how developments in new digital methods, such as blockchain technology, can facilitate trade, perhaps changing the need for customs brokers and other intermediaries in the future.

Acknowledgements I am grateful to the following people for providing useful information: Morten Aasgaard, Reidar Knutsen and Guillaume Lanquepin from the Norwegian Customs Directorate (on customs brokers, procedures and customs declaration data in Norway); and Øyvind Hagen from Statistics Norway (on customs declaration data). Copyediting by Susan Høivik is highly appreciated. I also wish to thank Jens Andvig, Frank Asche, Neil Balchin, Fenella Carpena, Fulvio Castellacci, Jon Fiva, Per Botolf Maurseth, Arne Melchior, Hans Martin Straume, Tommy Sveen and anonymous referees for useful comments.

Funding Research was funded by the Research Council of Norway, project 233836 'Traders in the Food Value Chain: Firm Size and International Food Distribution'. The funder had no role in study design; in the collection, analysis and interpretation of data; in the writing of the report; and in the decision to submit the article for publication.

Open Access This article is licensed under a Creative Commons Attribution 4.0 International License, which permits use, sharing, adaptation, distribution and reproduction in any medium or format, as long as you give appropriate credit to the original author(s) and the source, provide a link to the Creative Commons licence, and indicate if changes were made. The images or other third party material in this article are included in the article's Creative Commons licence, unless indicated otherwise in a credit line to the material. If material is not included in the article's Creative Commons licence and your intended use is not permitted by statutory regulation or exceeds the permitted use, you will need to obtain permission directly from the copyright holder. To view a copy of this licence, visit http://creativecommons.org/licen ses/by/4.0/.

\section{Appendix}

See Table 7. 


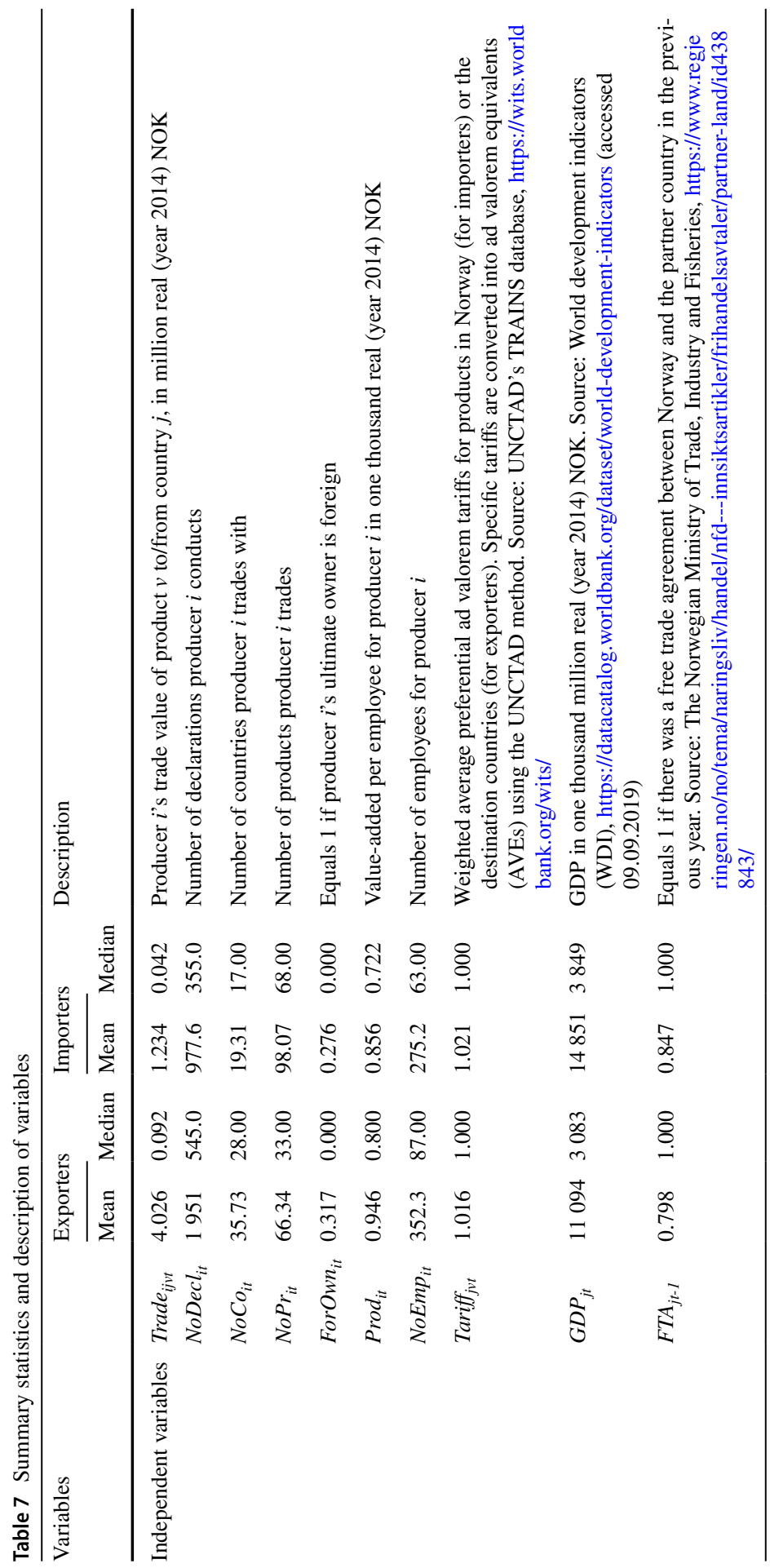




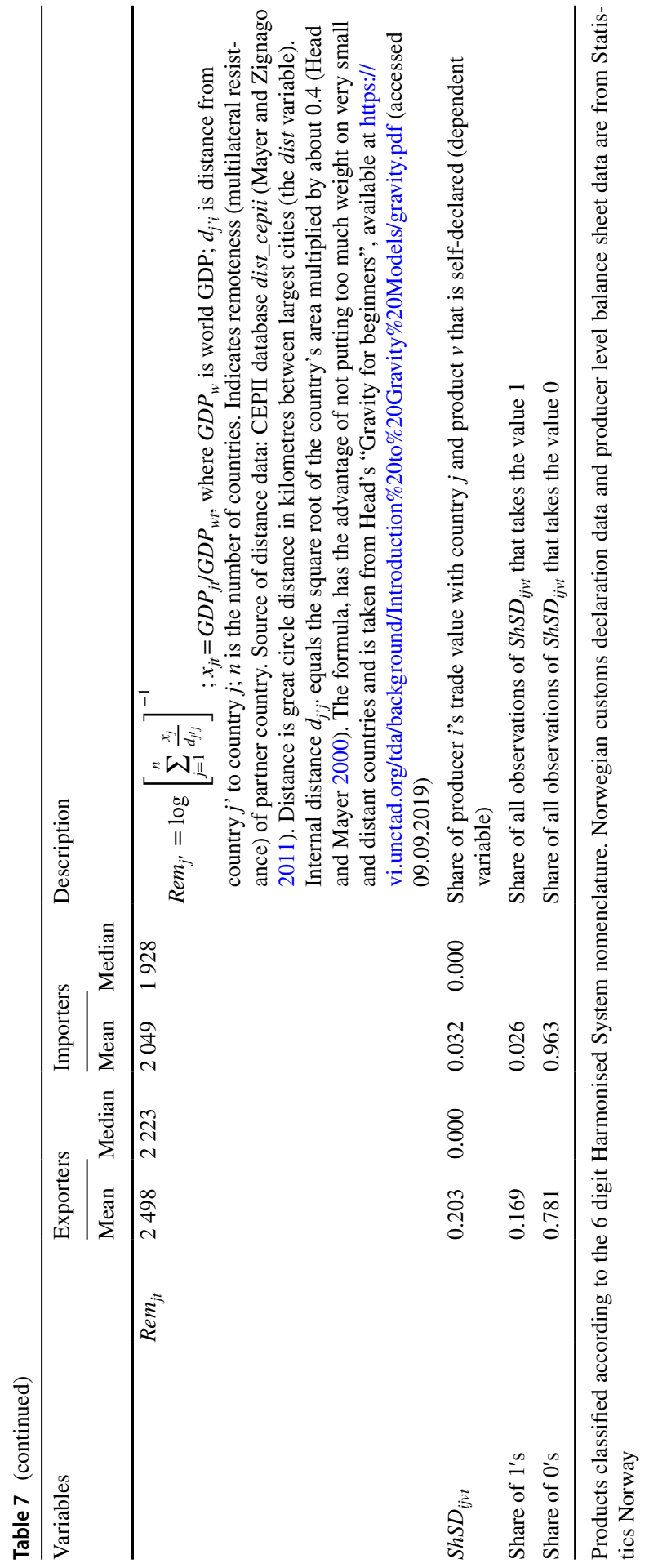




\section{References}

Abel-Koch, J. (2013). Who uses intermediaries in international trade? Evidence from firm-level survey data. The World Economy, 36(8), 1041-1064.

Ahn, J., Khandelwal, A. K., \& Wei, S. (2011). The role of intermediaries in facilitating trade. Journal of International Economics, 84(1), 73-85.

Akerman, A. (2018). A theory on the role of wholesalers in international trade based on economies of scope. Canadian Journal of Economics, 51(1), 156-185.

Albornoz, F., Calvo Pardo, H. F., Corcos, G., \& Ornelas, F. (2012). Sequential exporting. Journal of International Economics, 88(1), 17-31.

Andersen, J., Eidhammer, O., (2009). Logistikk og transportindustrien. Utvikling og tjenestetilbud. TØI rapport 1019/2009, Institute of Transport Economics, Oslo (in Norwegian).

Antràs, P., Fort, T. C., \& Tintelnot, F. (2017). The margins of global sourcing: Theory and evidence from US firms. American Economic Review, 107(9), 2514-2564.

Bai, X., Krishna, K., \& Ma, H. (2017). How you export matters. export mode, learning and productivity in China. Journal of International Economics, 104, 122-137.

Bernard, A. B., Blanchard, E. J., Van Beveren, I., \& Vandenbussche, H. (2019). Carry-along trade. The Review of Economic Studies., 86(2), 526-563.

Bernard, A. B., Grazzi, M., \& Tomasi, C. (2015). Intermediaries in international trade: direct versus indirect modes of export. The Review of Economics and Statistics, 97(4), 916-920.

Bernard, A. B., Jensen, J. B., Redding, S. J., \& Schott, P. K. (2012). The empirics of firm heterogeneity and international trade. Annual Review of Economics, 4(1), 283-313.

Bernard, A. B., Jensen, J. B., Redding, S. J., \& Schott, P. K. (2010). Wholesalers and retailers in US trade. American Economic Review, 100(2), 408-413.

Bernard, A. B., Redding, S. J., \& Schott, P. K. (2011). Multiproduct firms and trade liberalization. Quarterly Journal of Economics, 126(3), 1271-1318.

Blum, B. S., Claro, S., \& Horstmann, I. J. (2018). Trade costs and the role of international trade intermediaries. In B. A. Blonigen \& W. W. Wilson (Eds.), Handbook of International Trade and Transportation. Camberley, Surrey: Edward Elgar Publishing.

Bluhm, R. (2013). Fhetprob: A fast qmle stata routine for fractional probit models with multiplicative heteroskedasticity. Manuscript. https:/www.richard-bluhm.com/wp-content/uploads/2013/02/fhetprob.pdf

Chaney, T. (2014). The network structure of international trade. American Economic Review, 104(11), 3600-3634.

Crozet, M., Lalanne, G., \& Poncet, S. (2013). Wholesalers in international trade. European Economic Review, 58, 1-17.

Felbermayr, G., \& Jung, B. (2011). Trade intermediation and the organization of exporters. Review of International Economics, 19(4), 634-648.

Frémont, A. (2009). Empirical evidence for integration and disintegration of maritime shipping port and logistics activities. OECD/ITF Joint Transport Research Centre Discussion Paper. https://doi. org/10.1787/227565346707.

Grainger, A. (2008). Customs and trade facilitation from concepts to implementation. World Customs Journal, 2(1), 17-30.

Grazzi, M., \& Tomasi, C. (2016). Indirect exporters and importers. Review of World Economics, 152(2), 251-281.

Head, K., \& Mayer, T. (2000). Non-Europe: The magnitude and causes of market fragmentation in the EU. Weltwirtschaftliches Archiv/Review of World Economics, 136(2), 284-314.

Kropf, A., \& Sauré, P. (2014). Fixed costs per shipment. Journal of International Economics, 92(1), $166-184$.

Langley, C. J., Jr., Allen, G. R., \& Dale, T. A. (2004). Third-party logistics study results and findings of the 2004 ninth annual study. Utrecht, The Netherlands: Capgemini Consulting.

Leahy, S. E., Murphy, P. R., \& Poist, R. F. (1995). Determinants of successful logistical relationships: A third-party provider perspective. Transportation Journal, 35(2), 5-13.

Lieb, R., \& Bentz, B. A. (2002). The use of third-party logistics services by large American manufacturers, the 2002 survey. Supply Chain Forum, 3(2), 2-100.

Maurseth, P.B. and Medin, H. (2019) Internet use, intermediaries and international trade. NUPI working paper 885 .

Mayer, T. \& Zignago, S. (2011). Notes on CEPII's distances measures (GeoDist). CEPII Working Paper 2011-2025, December 2011. Paris: CEPII. https://www.cepii.fr/PDF_PUB/wp/2011/wp2011-25.pdf 
McCann, F. (2013). Indirect exporters. Journal of Industry, Competition and Trade, 13(4), 519-535.

Melitz, M. (2003). The impact of trade on intraindustry reallocations and aggregate industry productivity. Econometrica, 71(6), 1695-1725.

Neyman, J., \& Scott, E. L. (1948). Consistent estimation from partially consistent observations. Econometrica, 16(1), 1-32.

Papke, L. E., \& Wooldridge, J. M. (2008). Panel data methods for fractional response variables with an application to test pass rates. Journal of Econometrics, 145(1-2), 121-133.

Rauch, J. E. (1999). Networks versus markets in international trade. Journal of International Economics, 48(1), 7-35.

Verwaal, E., \& Donkers, B. (2003). Customs-related transaction costs, firm size and international trade intensity. Small Business Economics, 21(3), 257-271.

Utar, H. (2017). Characteristics of international trade and their location in the supply chain. In B. J. Christensen \& C. Kowalczyk (Eds.), Globalisation Strategies and effects. Berlin: Springer.

Wooldridge, J. M. (2005). Simple solutions to the initial conditions problem in dynamic, nonlinear panel data models with unobserved heterogeneity. Journal of Applied Econometrics, 20(1), 39-54.

Wooldridge, J. M. (2019). Correlated random effects models with unbalanced panels. Journal of Econometrics, 211(1), 137-150.

WTO. (2016). World Trade Report 2016. Levelling the trading field for SMEs. Geneva: World Trade Organization.

Publisher's Note Springer Nature remains neutral with regard to jurisdictional claims in published maps and institutional affiliations. 